\title{
Toward Better Research on Stress and Coping
}

\author{
Richard S. Lazarus \\ University of California, Berkeley
}

In commenting in considerable detail on the four main articles in the special section on stress and coping, the author comes to two main conclusions: First, there is an increasing amount of high quality research on stress and coping that suggests the field is finally maturing, and this research may help reduce the long-standing gap between research and clinical practice. Second, this research is increasingly using badly needed research designs that have not hitherto been sufficiently emphasized, such as longitudinal or prospective designs, focused on observations that are day-to-day, microanalytic, and in-depth, and that are compatible with a holistic outlook. The author also addresses the role of positive emotion in coping, the concept of defense as it is dealt with nowadays, and the task of evaluating coping efficacy.

$\mathbf{F}$ or more than 50 years, my research and theoretical efforts have centered on the topics of stress, the emotions, and the coping process. For this reason and the fact that in their introduction Somerfield and McCrae (2000, this issue) cite me as a leader in this field, I am very happy to have been asked to comment on the four articles in this section (Coyne \& Racioppo, 2000; Cramer, 2000; Folkman \& Moskowitz, 2000; Tennen, Affleck, Armeli, \& Carney, 2000). I am pleased that the section brings an overview of the current state of the literature before the entire field, and I feel a strong obligation to serve this area of the field in which I have been a pioneer.

A discussant of others' work should at the outset indicate the biases that inform comments to come. In my case, I have been plowing and seeding the field of stress, coping, and the emotions since the late 1940s. My frame of reference has always been an epistemological, ontological, and theoretical approach that emphasizes individual differences, the cognitivemotivational-relational concepts of appraisal and coping, and a process-centered holistic outlook (Lazarus, 1999c, in press). The conceptual bottom line of my approach is the relational meaning that an individual constructs from the person-environment relationship. That relationship is the result of appraisals of the confluence of the social and physical environment and personal goals, beliefs about self and world, and resources.

My commentary is organized around five topics, most of which were raised by the contributors to the section. Those topics are as follows: (a) the quality of coping research; (b) the gap between clinical practice and research; (c) research designs in coping research, where $I$ also discuss two research programs included in this special section, namely, those of Tennen et al. (2000) and Folkman and Moskowitz (2000); (d) the concept of ego defense and Cramer's (2000) discussion of it; and (e) the task of evaluating coping efficacy.

\section{The Quality of Coping Research}

A premise that appears again and again in this section is that for quite a few years research has disappointed many who had high hopes it would achieve both fundamental and practical knowledge about the coping process and its adaptational consequences. Although I recently expressed such disappointment (Lazarus, 1993a, 1997, 1998a), I am now heartened by positive signs that there is a growing number of sophisticated, resourceful, and vigorous researchers who are dedicated to the study of coping.

In light of the recent accomplishments by those researchers, some of my previously dour, pessimistic thoughts about the state of the art now seem overstated. Therefore, one of the main themes of my commentary is the presence of much greater hope for the future prospects of this field. This more optimistic position stands in contrast with what Coyne and Racioppo (2000) have written, which seems to be unduly negative. Although I agree with many of the points they made, their methodological analysis disappoints me for three main reasons.

First, they offer mainly a series of criticisms, some of them unfair. This endeavor does more harm than

Editor's note. Mark R. Somerfield and Robert R. McCrae developed this Psychology in the Public Forum section.

Author's note. Richard S. Lazarus, Department of Psychology, University of California, Berkeley.

Correspondence concerning this article should be addressed to Richard S. Lazarus, 1824 Stanley Dollar Drive \#3B, Walnut Creek, CA 94595-2833. 
good. Second, they provide little in the way of solutions. For example, to describe research in this field, they use the extraordinarily denigrating image of a slum that should be razed rather than reconstructed. Analyses in which authors are intent on damning the whole coping research enterprise by not clearly distinguishing the wheat from the chaff are not needed; plenty of good material can increasingly be found.

Coyne and Racioppo's (2000) overzealousness is exemplified in their discussion of coping questionnaires. I speak as one who has developed a coping questionnaire (Folkman \& Lazarus, 1988). I agree that questionnaires should be thought of as an initial rather than a final step toward understanding and that they do not allow psychologists to go below the surface to identify goals and situational intentions, especially those of which the individual is unaware. Nevertheless, they permit the study of large samples and the quantification of the coping process, which under some circumstances is useful and important.

Coyne and Racioppo's (2000) overzealousness is also exemplified by their discussion of confounding. Although this can, indeed, be a problem in coping research, they oversimplify and overemphasize the problem of confounding. For example, they present a strong warning about the risks of confounding, but those risks are hardly as great as portrayed. The danger of confounding is that measures of coping could contain some of the same variables-for example, distress or psychopathology - as the outcome measure of mental health. Thus, if the antecedent and consequent measures are essentially the same, any correlation between them would represent some degree of tautology rather than a causal explanation. Without specifying where the confounding lies in any particular study and without data demonstrating confounding, however, any assessment of risk is much too facile and misleading.

What Coyne and Racioppo (2000) fail to mention in their warning is that confounding is a difficult epistemological issue about which scientifically oriented scholars disagree. If a simple answer exists, it is that one should not draw implications about the risk of confounding without data to demonstrate that risk, and one should do so only if there is little or no room remaining for independent variance after the so-called confound has been eliminated. Coyne and Racioppo's heavily emphasized warning about this risk is greatly overdrawn. It is little more than supposition, based on a superficial impression that could easily be erroneous. The warning, which at first blush may sound like a wise defense of science, merely masquerades as wisdom.

The issue of confounding has always been troubling for psychology from a measurement standpoint. This was evident some years ago in a criticism made by Dohrenwend, Dohrenwend, Dodson, and Shrout (1984) that the Berkeley Stress and Coping Project's Hassles Scale, which first appeared in 1981 and was later given to a test publisher (see Lazarus \& Folkman,
1989), contained the same variable, psychopathology, that was also present in the outcome measure, psychological symptoms.

Lazarus, DeLongis, Folkman, and Gruen (1985) responded to this criticism by initially examining the issue of confounding from a broad scientific perspective. For example, they noted that correlational research involving social and psychological processes is likely to be characterized by some degree of circularity, which is very difficult to avoid. This circularity should not be fatal to the validity of the research conclusions, however, as long as a reasonable amount of the variance remains after the confound has been eliminated. In effect, confounding is relative and an empirical question.

Lazarus et al. (1985) also reported a new study in which many of the items of the Hassles Scale were rewritten to free it of the supposed confounding. The substantial correlations between hassles and psychological symptoms were not greatly changed by this manipulation, and they remained significant at the .001 level. Therefore, the impression of confounding suggested by Dohrenwend et al. (1984) was not borne out by the data.

Second, Coyne and Racioppo (2000) ignore what many others have said on the topic of coping research. In their introduction, Somerfield and McCrae (2000) note a number of such critiques, including two of mine (Lazarus, 1993a, 1997). Although Coyne and Racioppo cite the 1997 article, they fail to acknowledge that I had expressed many of the same methodological concerns they present here. I could easily agree with many of the concerns if they were directed at only the poorest research on coping. These concerns remind us of what psychologists should take into account when looking at coping research. Stated as they are, however, they often fail to constitute a properly balanced rendition of the methodological issues.

Third, and far more damaging to an accurate portrait of today's coping research, is that what Coyne and Racioppo (2000) say about an overreliance on coping questionnaires ignores the growing number of important current coping research programs that do not depend on such questionnaires. Their failure to cite this research can mislead readers who are not familiar with the literature on stress, coping, and emotion. Consider, for example, the current and continuing research on the caregivers of partners suffering and dying of AIDS by Folkman and her colleagues, which is referred to in Folkman and Moskowitz's (2000) article in this section. Although these researchers used the Ways of Coping Questionnaire (Folkman \& Lazarus, 1988), their main source of data included detailed and in-depth interviews and observations.

Their longitudinal research design and careful observations reveal in great detail powerful positive and negative emotional reactions of the caregivers before and after the tragic death of the men they cared 
for. These methodological virtues also made it possible to evaluate defensive and motivational features of the coping process. My high regard for this research is reinforced by widespread international praise for Folkman's research and ideas. It is, in my view, a first-class example of what can be done in coping research, but Coyne and Racioppo (2000) make no mention of it.

Coyne and Racioppo's (2000) criticism about questionnaires also does not apply to the research of Tennen et al. (2000), whose research I consider later in this article along with that of Folkman and Moskowitz (2000). In both these cases-Folkman and Moskowitz and Tennen et al.- their research has been ongoing for some years and published previously, so Coyne and Racioppo could easily have referred to it favorably. I found it easy to praise a number of other studies (Lazarus, 1999c) that were described in two recent edited books: one by Gottlieb (1997) that deals with chronic stress, the other by Eckenrode and Gore (1990) on the spillover of work to the family.

My main point is that although there is plenty of unhelpful research to complain about, there is also a substantial amount of promising solid-even creative-work on stress and coping. The fact that Coyne and Racioppo (2000) ignore these worthy examples and the published statements of other serious scholars seems unfortunate and misleading.

\section{Gap Between Clinical Practice and Research}

Coyne and Racioppo (2000) criticize the failure of stress and coping research to be useful in clinical practice. Many psychologists in this field did, indeed, hope that their research would have practical clinical value, and the studies I have been applauding are, in fact, quite relevant to clinical practice. However, as Somerfield and McCrae (2000) point out in their introduction, there has also been a failure on the part of clinicians to acknowledge the complexity of the task of making the research applicable. Many variables are involved in how people cope and the outcomes of coping. These include the different kinds of stress and their details, such as whether a loved one died in dragged-out misery or quickly and unexpectedly; individual differences in personality traits and resources; the interpersonal and cultural context; and the diverse criteria that should be used for evaluating the success of coping efforts, such as subjective well-being, somatic health, and criteria based on societal values. Given the great scope and difficulty of the task, can anyone really believe that the task of understanding what people are like and how change can be promoted is a simple one to be achieved overnight, so to speak, or in a few research programs?

The lack of collaboration and communication between researcher and clinician, another criticism made by Coyne and Racioppo (2000), is a familiar and painful topic for most psychologists. This highly complex and political issue has been previously addressed with wisdom by others (e.g., Beutler, Williams, Wakefield, \& Entwistle, 1995). It is disheartening that so few researchers accept the responsibility of making the relevance of their research clear to the practitioner, and so few clinicians pay attention to such research even when it has implications for clinical practice. The gap between practitioner and researcher has a long and unfortunate history, with some psychology departments refusing to offer clinical training and others, such as my own, having experienced bitter struggles over this issue in the past (for a more detailed look at the Berkeley struggles, see Lazarus, 1998a, $1998 \mathrm{~b})$. It is also illustrated by the separate existence of the American Psychological Association and the American Psychological Society. This history undoubtedly undermines what could be useful collaboration between researchers and clinicians in advancing our understanding of the stress and coping process.

\section{Research Designs}

In the upcoming text, I highlight certain research methods-for example, longitudinal, prospective, and microanalytic approaches; in-depth observation; and holism-all of which I consider essential, if not just advantageous, for the study of stress, emotion, and coping. I also draw on Tennen et al.'s (2000) and Folkman and Moskowitz's (2000) research as concrete illustrations. I may seem to digress briefly as I set the stage by first speaking generally about research.

\section{Analysis and Synthesis (and Holism)}

The prime objective of basic research is to understand life and the world in which it exists. This understanding can then be validated, in part, by its ability to help psychologists predict human reactions under diverse conditions and demonstrate its utility in practical applications. There are two main ways to understand a phenomenon. One is the standard scientific approach, which these days depends almost entirely on analysis, and in which complex phenomena are broken down into smaller, presumably more elemental explanatory variables, each of which is only a part of the whole. This canon has been revered as the standard causeand-effect research style of reductive science, which includes psychology. This approach has allowed researchers to achieve impressive knowledge in the physical and biological sciences, and it provides a considerable degree of practical control over the world, although I am not convinced it is ideal for many of the most important topics of psychology.

Although an analytic, cause-and-effect epistemology aims at exploring the functional connections among the component parts, it also fractionates the phenomena with which the researchers began, thereby limiting understanding, especially when the parts are treated as if they were the whole. An important step is often missing, namely, the effort to reconstruct the 
whole so that the phenomena under study are restored to the form in which they appear in nature. This deficit has led many psychologists to advocate another approach to understanding, not as a substitute for the analytic approach but as a necessary complement. Its essence is the full and accurate description of phenomenal wholes, which is what is observed in nature and conceptualized with abstract categories constructed by researchers themselves; detailed description is as important to science as is the search for causal variables.

Here psychologists might follow the lead of John Dewey $(1894,1896$; Dewey \& Bentley, 1949), the philosopher-psychologist, who argued for the importance of synthesis. When psychologists study stress, emotion, and coping, they want to accurately portray the behavioral display and the experience of emotions and to say what they are like. To understand stress, emotion, and coping fully, psychologists need to take into account both levels of abstraction, that is, the parts they are treating as causes and the organized (or synthesized) wholes that comprise the parts.

Thus, psychological stress can be thought of as part of a complex, organized biosocial-psychological entity or whole, which psychologists refer to as an emotion, such as anger, fear, shame, joy, or love. Emotions are broader, more inclusive concepts than stress in that they comprise both positive and negative emotional states. Coping is an integral part of an emotion, but it is not the whole. The methods one uses to study emotion and its component parts depend on which of the two modes of scientific understanding one favors, analysis or synthesis. Although they complement each other, their scientific tasks are sufficiently distinctive to require different lines of thought and research methods.

The task of analytic research-that is, to identify causal variables and show how they work-requires a timeline of antecedents and consequences, as in John Stewart Mill's (1843/1949) logical canons of experimentation. If the appropriate logic is followed, it becomes possible to demonstrate that variable $\mathrm{A}$ is a cause of variable $B$ by showing that if $A$ is not present $B$ does not occur. Nevertheless, from a broader point of view, the timeline must not be viewed as rigidly fixed; rather, a more modern recursive frame of reference should be adopted, in which any of the variables can serve as an antecedent, a mediator, a moderator, or a consequence, although not at exactly the same moment. Cross-sectional research can only demonstrate a correlation between $\mathrm{A}$ and $\mathrm{B}$; it cannot prove causality. For causation in stress and coping to be understood, longitudinal research is needed.

\section{Longitudinal (or Prospective) Research}

Prospective longitudinal research allows researchers to try to predict later events from measures obtained earlier. This requires repeated measurements on the same persons who are observed from Time I to Time N and across diverse circumstances. What distinguishes longitudinal from cross-sectional research is not the duration or size of the study. Rather, the research design must be within-subjects and prospective (Lazarus, 1999c). This kind of research allows researchers to identify psychological structures, that is, stable personality dispositions (or traits). It also allows the identification of changes (or processes) in psychological reactions over time and diverse conditions. Both are important.

The dilemma created for the researcher is that so much time and energy must be spent obtaining repeated measures with the same persons that the size of the participant sample is inevitably limited by the cost of obtaining those repeated measures. This limitation makes it all but impossible to select a representative sample that would permit secure generalizations about the average person or particular classes of persons.

With an ipsative-normative version of longitudinal research, researchers seek a solution to this dilemma by selecting a particular sample, albeit a limited one, while recognizing that generalizations to other samples cannot be depended on without additional studies using different samples. There is no way out of the dilemma: To adhere to one value, one has to sacrifice the other, at least temporarily. Ipsative-normative research designs permit the delineation of what the persons being studied are like individually and how they feel, think, and act, which is revealed by repeated measurement and an examination of the ways and conditions under which they relate to the world. Ipsative refers to within-person comparisons, and normative refers to comparisons between- or amongpersons. Either perspective can be dominant, and they complement each other. For those who are especially interested in the rationale involved here, I know of no clearer discussion of this than was published long ago by Broverman (1962).

\section{Exemplary Research Designs}

Tennen et al. (2000) summarize research that uses both a within-persons and an across-persons research design-in effect, an ipsative-normative version of longitudinal research - to study the clinical problems of pain, depression, and alcohol consumption in a programmatic effort to link theory, research, and clinical practice. A highly desirable feature of their research is the emphasis on day-to-day variations, that is, changes (processes) that take place over time and conditions. Their research is also microanalytic in that they look closely at the details of what is happening intrapersonally as well as interpersonally.

Tennen et al.'s (2000) article provides an excellent example of how to conduct research that follows the epistemological and ontological positions I identified earlier. The focus is on individual differences, cognitive-motivational-relational meaning-centered mediation (e.g., appraising), a longitudinal (or prospective) research style, and an effort to obtain 
microanalytic data in a framework that is processcentered and holistic. Notice that research of this kind is most like the assessment and treatment procedures used in clinical practice, but it also draws on a sufficient number of participants to permit generalizations beyond a sample size of one. I consider these outlooks and methods to be hallmarks of the best shortterm research on stress, coping, and the processes whereby emotional reactions occur and affect social functioning. Long-term research of this sort is needed for the study of stress, coping, and emotions as factors in health and illnesses, such as cancer and heart disease, which take a long time to develop and emerge. The logical and empirical case Tennen et al. make for an emphasis on within-persons comparisons and an intensive focus on day-to-day processes is impressive. Their data also confirm the utility of both withinpersons comparisons and day-to-day analyses.

Tennen et al. (2000) point out that the questions addressed by between-persons research designs are entirely different from those addressed by withinpersons designs. Their own findings on coping and alcohol consumption differ when analyzed from one or the other of these two perspectives, echoing Epstein's (1983) earlier observation that correlations among emotions vary depending on whether they are studied in the same person across occasions or in different persons on the same occasion.

Because these two levels of analysis address very different questions, we are not surprised by this discordance. What does surprise us, however, is that investigators continue their attempts to answer inherently within-person questions regarding stress, coping, and psychological adaptation with between-person research designs and analytic strategies. (Tennen et al., 2000, p. 628).

This principle is also instantiated in Tennen et al.'s (2000) findings about the influence of depression on the experience of pain. If depression and pain are studied with a between-persons research design, persons who are depressed report more pain than do those who are not depressed. They also engage in more pain catastrophizing and believe that their coping strategies were relatively inefficacious. So far so good from a normative standpoint.

However, within-person analysis shows that patients with a history of depression are less able to inhibit pain catastrophizing the day after a good night's sleep compared with those who had never been depressed. What is striking, in effect, is that a day-to-day examination of pain reveals more accurately than between-person analysis the extent to which depression affected the pain experience. It also shows that pain varies greatly depending on what takes place in the coping process from day to day. The conclusion Tennen et al. (2000) reach, that "a pain diary may yield a different picture of the pain experience than would a summary obtained at an office visit" (p. 631), is very important to the future development of the stress and coping literature.

But what about coping? A tendency has emerged in coping research to pit the problem-focused and emotion-focused coping functions against each other to compare their respective efficacy. However, this is a strategic mistake, as I said in Lazarus (1993b, 1999c). It is misleading to separate these two functions of coping and compare their efficacy because although conceptually distinguishable, both strategies are interdependent and work together, one supplementing the other in the overall coping process. The distinctions between them should not be taken too literally by comparing their individual capacities to influence adaptational outcomes. For a picture of how people cope, psychologists need to study how both functions, and perhaps the balance between them, work and affect each other and the adaptational outcome: in effect, how they operate as a single coping unit.

The studies of daily coping with rheumatoid arthritis by Tennen et al. (2000) confirm the utility of this ontological position. Their data show that the two functions of coping, problem- and emotion-focused, usually occur together as they did in the early research of Lazarus and Folkman (1984). What is even more revealing in their data is that when they compared the relative probability of the occurrence of emotionfocused coping, the likelihood was 4.4 times greater on a day when problem-focused coping had occurred than on a day without it. Here, intraindividual analysis of day-to-day coping provides a far richer and more provocative picture of how coping works than when the two functions of coping are treated as independent and in competition with each other with respect to their adaptational consequences. Referring to these findings, they conclude:

Not only was today's emotion-focused coping predicted by yesterday's problem-focused coping, but this cross-day association was itself a function of the change in pain from yesterday to today. An increase in today's pain over yesterday's pain increased the likelihood that problem-focused coping yesterday would be followed by emotion-focused coping today. In other words, when efforts to directly influence pain are not successful (as evidenced by an increase in next-day pain), the next day people may try harder to adjust to that which cannot be readily changed. At the risk of belaboring the obvious, we stress that these associations cannot be ascertained through cross-sectional or several wave longitudinal designs. We suspect that they would evade in-depth interviews ... or, worse, that participants would reconstruct associations on the basis of unexamined heuristics, personal theories, or a single recent or particularly distressing coping encounter. (pp. 632-633)

Given that psychologists have been presented with mainly cross-sectional coping research in the past, this analysis becomes important methodologically as 
a clear demonstration of the positive value of prospective, detailed examinations of the day-to-day interplay of problem- and emotion-focused coping with pain, alcohol consumption, and depression. This is surely a way in which psychologists can learn from well-designed and carefully delineated stress, coping, and emotion research.

\section{The Possible Role of Positive Emotion in Coping}

Folkman and Moskowitz (2000) provide an extensive overview of arguments and observations in favor of an emerging interest that is currently being referred to as positive psychology (see Seligman \& Csikszentmihalyi, $2000 \mathrm{~b}$, for a definition). They also discuss research findings from their AIDS research project, which conforms to an ipsative-normative research style and suggests that positive affect may be a favorable condition for coping with the severe and prolonged stress of being the caregiver of a terminally ill partner. Folkman and Moskowitz (2000) argue persuasively that one of the major deficits in research and theory on the coping process has been the failure to appreciate the role of positive affect. I prefer to speak of emotion rather than affect because the former is a more inclusive concept that includes impulses to act and embodied emotional states. However, when referring to their work I follow their preference.

Some of Folkman and Moskowitz's (2000) findings and proposals could guide psychologists toward an understanding of how positive affect might help prevent emotional breakdown under severe and prolonged stress. The authors propose a number of mechanisms that seem promising and could provide a conceptual basis for future research, although the issues and how they might be addressed are by no means simple. Their article offers three premises on the role of positive affect in coping and adaptation that are provocative and potentially useful for those who want to keep their bearings in this complex field. In the first premise, they say, "positive affect can cooccur with distress during a given period" (p. xxxx). This theme allows for the possibility that emotions commonly referred to as positively valenced are often experienced as negative or distressing, and vice versa: Emotions said to be negatively valenced are often experienced as positive (see also Lazarus, in press).

Consider a few examples of so-called positive emotions, such as love and hope (see Lazarus, 1999b, $1999 \mathrm{c})$. Some forms of love are very distressing for the one who loves, such as when it is unrequited or in the process of fading or being lost. In American culture, hope is generally considered to be a positive state of mind, but it is almost certainly conjoined with anxiety because the outcome of hoping is never assured. The same principle, incidentally, applies to the emotions of relief, happiness, and pride.

In contrast, anger, which is usually considered a negatively valenced emotional reaction, is often experienced as positive, at least under some conditions and for some persons. For example, people who are made angry and express the anger interpersonally often feel good about it: They have done something to repair a personal slight to their self- and social esteem, which leads them to feel more in command of the situation and less ashamed or inadequate. However, this good feeling may only be temporary, because the person who expressed the anger may have produced longterm damage to the social relationship that may not be recognized at the outset.

Some emotions, such as love and hope, should not be labeled unequivocally positive in valence, because in real life they are often experienced as negative or mixed with negative feelings. To be positively valenced requires an appraisal of what is happening that is supportive or goal-congruent (Lazarus, 1991). Likewise, other emotions, such as anger, should not be labeled unequivocally negative, because in real life they are often experienced as positive or mixed with positive feelings. To be negatively valenced requires an appraisal that what is happening is thwarting or goal-incongruent.

Folkman and Moskowitz's (2000) second premise is that "positive affect in the context of stress has important adaptational significance of its own" (p. 648 ). The authors discuss a number of routes whereby positive affect might influence coping and stress reactions and, conversely, whereby coping can generate positive affect. This is groundbreaking, because the simplistic way that coping and the emotional process are often portrayed is implicitly rejected in favor of a role for coping in the emotional life that had not previously been considered.

The most important data from Folkman and Moskowitz's (2000) research relevant to this premise comes from evidence about the active efforts of the caregivers to make positive events happen and to imbue them with positive meaning. They not only organized these events but strove to view even relatively trivial events as positive and gained psychologically from doing so.

Their third premise, prefigured in what I said about the second, states that "coping processes that generate and sustain positive affect in the context of chronic stress involve meaning" (Folkman \& Moskowitz, 2000, p. 648). This is the most important premise in that it views stress, coping, and emotion as dependent on the relational meaning that an individual person constructs from the person-environment relationship. The role of relational meaning in emotion is one of the unresolved issues that fueled the cognitionemotion debates of the recent past (Lazarus, 1999a). Folkman and Moskowitz's empirical observations provide an aura of truth to their third premise. Much more remains to be thought and done to link positive affect, coping, and adaptational outcomes and to decipher the psychosocial dynamics of the linkage, but Folkman's 
project has made a promising start. It is also an interesting and relatively unusual fusion of clinical work and research.

Given the Folkman and Moskowitz (2000) concern with positive psychology, the January 2000 issue of the American Psychologist, a special issue focused on positive psychology and guest edited by Martin E. P. Seligman and Mihaly Csikszentmihalyi (2000a), merits mention. Articles were chosen to exemplify the effort, certainly laudable, to improve the quality of life by promoting psychological strengths. According to the editors, the main topics included what makes one moment better than the next, subjective well-being, optimal experience, optimism, happiness, self-determination, and positive emotions and physical health (Seligman \& Csikszentmihalyi, 2000b). Other articles focused on excellence, creativity, giftedness, and positive psychological development. Positive psychology appears to encompass a wide range of topics and perspectives that at this stage, before a comprehensive conceptual approach to it has evolved, is probably all to the good.

However, it might be worthwhile to note that the danger posed by accentuating the positive is that if a conditional and properly nuanced position is not adopted, positive psychology could remain at a Pollyanna level. Positive psychology could come to be characterized by simplistic, inspirational, and quasi-religious thinking and the message reduced to "positive affect is good and negative affect is bad." I hope that this ambitious and tantalizing effort truly advances what is known about human adaptation, as it should, and that it will not be just another fad that quickly comes and goes. The quality and thoughtfulness of many of the articles, such as the editors' introduction (Seligman \& Czikszentmihalyi, 2000b) and Peterson's (2000) treatment of optimism, are reassuring in that regard.

\section{The Concept of Ego Defense}

I have long been convinced that research on stress, coping, and the emotions must address unconscious processes and ego defense. There is a growing conviction that a large proportion of human appraisals occur without self-awareness of the factors that influence the emotion process. Defense is one of these factors. It cannot be effective if the defending person is fully aware of the process and its motivation. When I used the term in-depth earlier, I had in mind research strategies that could be used to study unconscious processes, including defenses.

It pleases me, therefore, to see Cramer's (2000) scholarly defense of the concept of defense. The topic is an important but perplexing one for research and theory on stress, coping, and the emotions (see Lazarus \& commentators, 1995). To overlook it is to risk not covering the ground of this field adequately and to restrict the study of coping to only deliberate and conscious decision making. Cramer's article, there- fore, not only belongs in this section but appears at a time when most of the interest in unconscious processes has been centered on social cognition rather than on defense.

However, Cramer (2000) suggests that there seems to be a resurgence of interest in the idea of defense even though that concept has often been relabeled, although she does not say why. I suspect relabeling reflects the desire to emphasize variables and processes other than those found in the Freudian conception of defense. Even some psychoanalytically oriented psychotherapists no longer refer to the process of defense per se. A prominent example is the San Francisco Psychotherapy Research Group. Their approach is based on J. Weiss's $(1986,1990)$ outlook on psychopathology. It focuses on the ways patients in treatment learn to fight back against pathogenic beliefs about themselves and their interpersonal world, which serve as the underlying basis of their distress and dysfunction. These beliefs are said to arise from traumatic experiences with parents and siblings. Patients repeat the past while seeking experiences with the therapist (as in the transference relationship) that could help to disconfirm the pathogenic belief (Sampson, 1992, 1994).

Nowhere in this clinical analysis of the origins of emotional dysfunction and the therapeutic process is the word defense used. Yet, it is clear that patients are protecting themselves against sources of distress they have been dealing with badly, which is presumably why they want to see themselves and the world more realistically through psychotherapy. Nevertheless, these patients appear to be using what psychoanalytic therapists and researchers once referred to as defense, another example of relabeling to emphasize psychodynamic processes that are now more to their liking.

Cramer (2000) recognizes that laboratory experiments, which once represented the dominant pattern of research on defense, have never been the most appropriate research strategy with which to address the concept and how it works. Cramer is not, nor am I, convinced that questionnaires are an adequate substitute. However, I was disappointed that given the controversial nature of the concept of defense and the efforts to relabel it, Cramer did not define the essential meaning of the concept nor tell how a defense can be identified. If she had, it might have helped readers understand why even the relabeled process, in social psychology and selected versions of psychoanalytic thought, research, and treatment, might still be about defense and not something else.

My main conceptual quarrel is with Cramer's (2000) uncritical acceptance of a hierarchical outlook on defense. Some defenses, such as denial, are said to be more developmentally immature than others and, therefore, pathological in adults. This conflates developmental maturity with adaptiveness, which is a faulty position that had been adopted by Menninger, Haan, 
and Vaillant. It is faulty because one needs to recognize that denial, which has traditionally been viewed in adults as immature and pathological, is sometimes maladaptive and sometimes adaptive, depending on the person and the threatening context (Lazarus, 1983). 1 suspect that everyone uses denial from time to time, but it is certainly not always pathogenic or pathological. If defense is emphasized as a trait, it becomes more difficult to view it as a process that depends to some degree on the circumstances.

Somerfield and McCrae (2000) point to the history of defense and coping, the cognitive revolution, and the widespread acceptance of the principle of cognitive mediation. Responding to Cramer's (2000) reasonable claim that the scientific premise of defense still requires validation, they suggest a multimethod approach assessing contradictions among self-reports, visible actions, and physiological measurements. Until recently, I took the same position, but I have begun to have second thoughts about it. In Lazarus (1999c) I pointed out that if contradictions between different sources of data are to be a reliable way to identify the process of defense, there must be substantial correlations under nondefensive conditions between the various data sources. Otherwise, the contradictions cannot be ascribed dependably to defense. Yet, each of the three main data sources are influenced by different although overlapping causal factors. Thus, physiological measures are captives of the demands for energy mobilization, and, when these demands are not controlled, psychological factors remain obscure and difficult to verify. Verbal reports depend on the knowledge of the truth, the willingness to report it, and the ability to recognize it. Further, actions are responsive to social opportunities and constraints.

The main basis of my doubts about this multileveled solution is that there has not yet been a programmatic attempt to study these correlations. The suspicion remains that the relationships among the different response systems are actually quite weak, and this threatens the use of discrepancies between response systems as a dependable way of identifying defenses. The magnitude of these correlations also depends on how they are obtained, that is, whether they are based on inter- or intraindividual data collection methods. Many years ago Lazarus, Speisman, and Mordkoff (1963) found the correlation between heart rate and skin conductance under stress and nonstress to be near zero when a between-subjects method of analysis was used, but it approached .50 when a within-subjects method was used. Problems such as these will have to be attacked systematically to apply contradictions effectively when making clinical and research inferences about defenses, regardless of how they are labeled.

\section{The Task of Evaluating Coping Efficacy}

In the introduction, Somerfield and McCrae (2000) point to one of the most vexing issues of research and theory on coping, namely, what is meant by effective coping and how to measure it (Lazarus \& commentators, 1995). This is a fundamental topic that warrants considerable thought, but I can only touch on it briefly here. Some modest theory about the issue exists: for example, the approach initiated some time ago by French, Caplan, and Van Harrison (1982) and applied to organizational stress. These researchers defined effective coping in terms of the quality of fit between environmental demands and the person. This fit, in turn, depends on the criteria used for effectiveness, such as subjective well-being, social functioning, and somatic health, and the relational meanings different individuals construct from it at any given moment or overall. This is the approach that Folkman and I favored (see Lazarus \& Folkman, 1984; Lazarus, 1999c). We too emphasized fit between person and environment, but unlike French et al. we view this relationship as constantly changing: in effect, as a process that depends on shifting work demands and settings and a fluid personal outlook.

Until now, research that might throw light on coping effectiveness has, by and large, been limited mainly to subjective well-being. A promising effort to extend the analysis of this issue has recently been made by Cignac and Gottlieb (1997). These authors produced a complex and detailed chart listing diverse classes of coping and types of appraisals of coping efficacy by the person who is coping. Their contribution substantially advances our previous classification, which emphasized mainly the problem- and emotion-focused coping functions (Lazarus \& Folkman, 1984). The most serious problem not yet faced in research is the need, mostly unfulfilled as yet, to go beyond subjective evaluations of the outcomes of coping to other criteria, such as behavioral, physiological, or objective health-related outcomes.

\section{Conclusion}

I end my comments by repeating the central theme, namely, that there is an increasing amount of high quality research of which those invested in the field of coping can be proud. Researchers have increasingly been adopting a number of principles that I (Lazarus, 1998a) and others (e.g., Jessor, 1996) have emphasized in opposition to many of the traditional methodological restrictions characteristic of the bygone era of radical behaviorism and logical positivism.

Researchers whose work I have cited here and quite a few others not cited are now doing much more than in the past. For example, they are examining psychological events more closely (microanalytically), in depth (relevant to levels of unconsciousness and defense), longitudinally, and more holistically as people cope with stress (as process), think (appraise and construct relational meanings), want, feel, and act in their struggle to advance their interests and adapt. 
More than in the past, these researchers are also increasingly attending to individual differences (both intra- and interindividual).

I believe there is now more reason to hope that the field of coping research is maturing. If I am right, the study of coping will expand rather than contract, resulting not necessarily in greater numbers of publications but in higher quality and more creative research that could add substantially to understanding and contribute to practical application. There are still too many potboilers, but if there is enough sound work, a surfeit of hasty, cross-sectional, one-shot studies, which, at this stage of the development of the field, might better be ignored, will be tolerable. I could not have made such a positive assessment seven years ago (in Lazarus, 1993a, or later in Lazarus, 1997) when I was critical of the superficiality and triviality of much of coping research, but I can more confidently do so now.

\section{REFERENCES}

Beutler, L. E., Williams, R. E., Wakefield, P. J., \& Entwistle, S. R. (1995) Bridging scientist and practitioner perspectives in clinical psychology. American Psychologist, 50, 984-994.

Broverman, D. M. (1962). Normative and ipsative measurement in psychology. Psychological Review, 4, 295-305.

Cignac, M. A. M., \& Gottlieb, B. H. (1997). Changes in coping with chronic stress: The role of caregivers' appraisals of coping efficacy. In B. H. Gottlieb (Ed.), Coping with chronic stress (pp. 245-267). New York: Plenum.

Coyne, J. C., \& Racioppo, M. W. (2000). Never the twain shall meet? Closing the gap between coping research and clinical intervention research. American Psychologist, 55, 655-664.

Cramer, P. (2000). Defense mechanisms in psychology today: Further process for adaptation. American Psychologist, 55, 637-646.

Dewey, J. (1894). The theory of emotion. Psychological Review, 1, $553-569$.

Dewey, J. (1896). The reflex arc concept in psychology. Psychological Review, 3, 357-370.

Dewey, J., \& Bentley, A. E. (1949). Knowing and the known. Boston: Beacon Press.

Dohrenwend, B. S., Dohrenwend, B. P., Dodson, M., \& Shrout, P. E. (1984). Symptoms, hassles, social supports, and life events: The problem of confounded measures. Journal of Abnormal Psychology, 93, 222-230

Eckenrode, J., \& Gore, S. (Eds.). (1990). Stress between work and family. New York: Plenum.

Epstein, S. (1983). A research paradigm for the study of personality and emotions. In M. M. Page (Ed.), Nebraska Symposium on Motivation. Personality-Current theory and research (pp. 92-154). Lincoln: University of Nebraska Press.

Folkman, S., \& Lazarus, R. S. (1988). Manual for the Ways of Coping Questionnaire. Palo Alto, CA: Consulting Psychology Press.

Folkman, S. K., \& Moskowitz, J. T. (2000). Positive affect and the other side of coping. American Psychologist, 55, 647-654.

French, J. R. P., Caplan, R. B., \& Van Harrison, R. (1982). The mechanisms of job stress and strain. Chichester, England: Wiley.

Gottlieb, B. H. (Ed.). (1997). Coping with chronic stress. New York: Plenum.

Jesssor, R. (1996). Ethnographic methods in contemporary perspective. In R. Jessor, A. Colby, \& R. A. Shweder (Eds.), Ethnography and human development: Context and meaning in social inquily (pp. 314). Chicago: University Chicago Press.

Lazarus, R. S. (1983). The costs and benefits of denial. In S. Breznitz
(Ed.), The denial of stress (pp. 1-30). New York: International Universities Press.

Lazarus, R. S. (1991). Emotion and adaptation. New York: Oxford University Press

Lazarus, R. S. (1993a). Coping theory and research: Past, present, and future. Psychosomatic Medicine, 55, 234-247.

Lazarus, R. S. (1993b). From psychological stress to the emotions A history of changing outlooks. Annual Review of Psychology, $44,1-21$.

Lazarus, R. S. (1997). Hurrah for a systems approach: Commentary on The utility of systems models of stress and coping for applied research: The case of cancer adaptation, by M. R. Somerfield. Journal of Health Psychology, 2, 158-160.

Lazarus, R. S. (1998a). Fifty years of the research and theory of $R$. S. Lazarus: An analysis of historical and perennial issues. Mahwah, NJ: Erlbaum.

Lazarus, R. S. (1998b). The life and work of an eminent psychologist: Autobiography of Richard S. Lazarus, New York: Springer.

Lazarus, R. S. (1999a). The cognition-emotion debate: A bit of history. In T. Dalgleish \& M. J. Power (Eds.), Handbook of cognition and emotion (pp. 3-19). Chichester, England: Wiley.

Lazarus, R. S. (1999b). Hope: An emotion and a vital coping resource against despair. Social Research, 66, 653-678.

Lazarus, R. S. $(1999 \mathrm{c})$. Stress and emotion: A new synthesis. New York: Springer.

Lazarus, R. S. (in press). Relational meaning and discrete emotions. In K. R. Scherer, A. Schorr, \& T. Johnstone (Eds.), Appraisal processes in emotion: Theory, methods, research. New York: Oxford University Press.

Lazarus, R. S., \& commentators. (1995). Vexing research problems inherent in cognitive-mediational theories of emotion-and some solutions. Psychological Inquiry, 6, 183-265.

Lazarus, R. S., DeLongis, A., Folkman, S., \& Gruen, R. (1985). Stress and adaptational outcomes: The problem of confounded measures. American Psychologist, 40, 770-779.

Lazarus, R. S., \& Folkman, S. (1984). Stress, appraisal, and coping. New York: Springer

Lazarus, R. S., \& Folkman, S. (1989). Manual for the study of daily hassles and uplifts scales. Palo Alto, CA: Consulting Psychologists Press.

Lazarus, R. S., Speisman, J. C., \& Mordkoff, A. M. (1963). The relationships between autonomic indicators of psychological stress: Heart rate and skin conductance. Psychosomatic Medicine, 25, 19-21.

Mill, J. S. (1949). A system of logic. London: Longmans, Green. (Original work published 1843)

Peterson, C. (2000). The future of optimism. American Psychologist, 55, $44-55$.

Sampson, H. (1992). The role of "real experience" in psychopathology and treatment. Psychoanalytic Dialogues, 2, 509-528.

Sampson, H. (1994). Repeating pathological relationships to disconfirm pathogenic beliefs: Commentary on Steven Stem's "needed relationships." Psychoanalytic Dialogues, 4, 357-361.

Seligman, M. E. P., \& Csikszentmihalyi, M. (2000a). Positive psychology [Special issue]. American Psychologist, 55(1).

Seligman. M. E. P., \& Csikszentmihalyi, M. (2000b). Positive psychology: An introduction. American Psychologist, 55, 5-14.

Somerfield, M. R., \& McCrae, R. R. (2000). Stress and coping research Methodological challenges, theoretical advances, and clinical applications. American Psychologist, 55, 620-625.

Tennen, H., Affleck, G., Armeli, S., \& Carney, M. A. (2000). A daily process approach to coping: Linking theory, research, and practice. American Psychologist, 55, 626-636.

Weiss, J. (1986). Part I: Theory and clinical observations. In J. Weiss, H. Sampson, \& the Mount Zion Psychotherapy Group (Eds.), The psychoanalytic process: Theory, clinical observation. and empirical research (pp. 3-138). New York: Guilford Press.

Weiss, J. (1990). Unconscious mental functioning. Scientific American, $262,103-109$ 